Article received on15th September 2011 Article accepted on 7 th October 2012

UDC: $78.01: 316.77$

$78.01: 81 ' 22$

\author{
Michael Austin* \\ Missouri Western State University \\ Department of Music
}

\title{
A CASE STUDY IN ANALYZING MUSICAL MULTIMEDIA USING UNITÉS SÉMIOTIQUES TEMPORELLES
}

Unités Sémiotiques Temporelles, (or USTs) are 19 phenomenologically perceived units that constitute a system developed at the Laboratoire Musique et Informatique de Marseille (MIM) to analyze and teach the composition of electro-acoustic music. This label instantly suggests a heavy emphasis on time and temporality; however, the name of each unit describes sound in terms of movement over time (Chute, Qui avance, Par vagues", etc.). In his essay, "Les Unités Sémiotiques Temporelles: Problématique et essai de définition”, François Delalande defines USTs as:

... A musical segment, which, without regard to context, has a precise temporal significance as a morphological organization of sound (the USTs themselves are equivalent, and abstract, segments that present, without regard to context, temporal significance as with similar modes of morphological organization). ${ }^{2}$ [translation mine]

\footnotetext{
* Author contact information: michael@mlaustin.com

1 "Falling, advancing, by waves", respectively.

${ }^{2}$ Laboratoire Musique et Informatique de Marseille, Les Unités Sémiotiques Temporelles: Éléments nouveaux d'analyse musicale, 1996, 19.
} 
USTs have traditionally been used to define temporally significant segments of music at the level of the Schaefferian sound object (objet sonore); however, Leigh Landy believes USTs are useful tools for analysis on several levels, writing:

This system offers a tool for analysis that works a three levels: the global morphological level, the semantic description level, and the level at which other characteristics that are found to be relevant are formulated. Its focus and its ability to be applied as a tool for classification are clear. Although not based solely on sound-based music analysis-it also covers the traditional forms of music-it has potential to be used to group perceived aural characteristics. Like Schaeffer's work, it relies on descriptive terminology to a large extent. It is a significant project, one of a very few. ${ }^{3}$

In order to address the notions of time and motion as expressed semantically by USTs, Delalande explains that "time will be accessible through duration or variations [over time] from one or more morphological qualities of the sound; however, the variations [over time] of qualities of the sound often represent movement" [translation mine].

USTS have been a successful tool in analyzing music and sonic phenomena at the level of the Schafferian "sound object (l'objet sonore) i.e. a singular and rather short fragment of material (usually only seconds in length) this paper, I demonstrate an expansion of the use of USTS to include any possible experiences of time and/or movement in a work - both in the experience of the sonic elements of a piece and in other constituent elements (vis. multimedia). Broadening the scope of time and movement that is analyzable by USTs provides a framework around which a theory of form in electroacoustical music and sonic art can develop. I will further demonstrate the usefulness of USTS as an analytical technique by analyzing Three Tales, Act III, Scene I ("Cloning") by Steve Reich and Beryl Korot as a model; by its nature as a mixed media piece, as with other works lying at the "edge of analysis", a phenomenological analysis of this piece would reveal important aspects of this work that traditional types of analyses would not. ${ }^{6}$ The process can be outlined in three steps:

${ }^{3}$ Leigh Landy, Understanding the Art of Sound Organization, Cambridge, MA, The MIT Press, 2007, 190.

${ }^{4}$ Ibid., 23.

${ }^{5}$ For further examples of previous uses of USTs, see Laboratoire Musique et Informatique de Marseille, Les Unités Sémiotiques Temporelles: Éléments nouveaux d'analyse musicale, 1996, 19, and Austin, Michael. The Phenomenological Impact of Interface on the Analysis of Digital Music and Sonic Art. Ph.D. Dissertation, University of Texas at Dallas, 2011.

${ }^{6}$ While this work is originally scored for vocalist, instrumentalists, and multimedia, only the video/DVD version of this work (by Nonesuch Records) will be examined due to its wider availability (i.e. one can order a copy of the DVD much more easily than one can find a live performance to attend). 
1. First, a work is broken down into significant sound objects, providing a means by which one can reduce the piece phenomenologically to the epoché (i.e. bracketed from outside meanings in order to analyze the characteristics of distinct sound objects as independent elements of the piece in question).

2. Next, the sound objects are mapped onto a descriptive map based on the analyst's experience of time. This mapping presents a unique way in which to observe relationships within a particular medium and among other constituent media via interface.

3. The analyst then applies semantic and morphological descriptions of each sound object and can introduce extra-musical meanings that may further influence the analysis of the work. ${ }^{7}$

As with most phenomenological investigations, an analysis using USTs begins with Edmond Husserl's notion of epoché, ${ }^{8}$ or bracketing, wherein the observer suspends any preconceptions of the world in order to observe a phenomenon as it exists. Husserl writes:

We put out of action the general positing which belongs to the essence of the natural attitude; we parenthesise everything which that positing encompasses with respect to being: thus the whole natural world which is continually "there for us" [...] If I do that, as I can with complete freedom, then I am not negating this "world" as though I were a solipsist; I am not doubting its factual being as though I were a skeptic; rather I am exercising the "phenomenological" ' $\dot{\pi} \chi \eta \eta$ ' which also completely shuts me off from any judgment about spatiotemporal factual being [...] Thus I exclude all sciences relating to this natural world no matter how firmly they stand there for me. ${ }^{9}$

This technique closely correlates with the acousmatic ${ }^{10}$ and Pierre Shaeffer's notion of "reduced listening" (or écoute réduite). Reduced listening is a "brack-

\footnotetext{
${ }^{7}$ These steps were developed in my doctoral dissertation. Austin, Michael. The Phenomenological Impact of Interface on the Analysis of Digital Music and Sonic Art. Ph.D. Dissertation, University of Texas at Dallas, 2011.

${ }^{8}$ Greek: غ̇ंoxń

${ }^{9}$ Edmund Husserl, Ideen zu einer reinen Phänomenologie und phänomenologishen Philosophie, Erstes Buch: Allgemeine Einfürung in die reine Phänomenologie (1913), Husserlania III, ed. K. Schuhmann (The Hague: Martinus Nijhoff, 1976); Ideas Pertaining to A Pure Phenomenology and to a Phenomenological Philosophy, First Book: General Introduction to a Pure Phenomenology, trans. F. Kersten, The Hague: Martinus Nijhoff, 1982, §32.

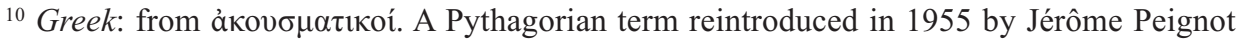
which considers the „distance which separates sounds from their origin”, i.e., an audio-only presentation of sound common to electroacoustic music. For some, the term is very precise and refers specifically to this listening situation. However, the term has gained wider usage, in describing a genre, which, to a large extent derives from the Musique Concrète tradition and is founded upon this listening situation. (Source: EARS: ElectroAcoustic Resource Site. http://www.ears.dmu.ac.uk/spip.php?rubrique216)
} 
eting off' of a sound object from its real or imagined source (and consequent meaning) and a mode of listening to the sound for its own sake, i.e. we listen to the qualities of the sound itself and not to the "object" to which it refers. Michel Chion further explains that reduced listening "reverses the twofold curiosity about causes and meaning (which treats sound as an intermediary allowing us to pursue other objects) and turns it back on to the sound itself. In reduced listening, our listening intention targets the event which the sound object is in itself (and not to which it refers) and the values which it carries in itself (and not the ones it suggests)". ${ }^{11}$ Reduced listening frees the sound object from our presuppositions of meaning and opens new possibilities for interpretation of sonic material; however, art is inherently bound by the cultural milieu within which it is created and/or perceived. Therefore, a thorough analyst of music or sonic art also takes the cultural implications and preconceived interpretations of a work into consideration. The sound object is merely the carrier for the invariants to be analyzed, and the UST, then is the tool that affords an analysis of both the experience of time and relationships among the constituent elements of a multimedia piece. In order, then, to analyze a piece using USTs, one must first reduce a work to its constituent "sound objects" but should not consider this morphological reduction to be an end in itself. In the case of "Dolly", these sound objects are often short sections of spoken texts. ${ }^{12}$

The piece begins with an image of a robot singing "And placed them in the Garden of Eden, to serve it and to keep it" (beginning 38:41, mm. 732-743 of "Bikini", the previous movement of Three Tales). While this melody is modal and resembles other common practice music, it also seems to be "floating", with no direction toward a cadential pattern or other closing figure. The next sonic event is a statement spoken by a woman: "Process is as follows..." While this statement semantically suggests more information will follow, the phrase as a sound object can be divided into two USTs (see Figure 1):

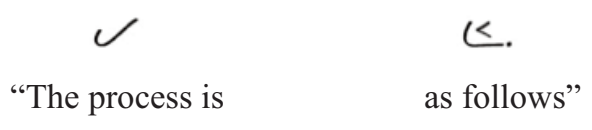

Figure 1. "The process is as follows..." analyzed as Propulsion + Conclusive USTs in Three Tales, Act III, Scene I

\footnotetext{
${ }^{11}$ Chion, Michel. Guide des objets sonores: Pierre Schaeffer et la recherche musicale. trans. John Dack and Christen North. 2009, Paris: INA-GRM, 1983, 30-31.

${ }^{12}$ I would like to point out the fact that, while in this paper USTs are used in succession, USTs can also be used in a nested, almost Schenkerian, fashion that can lead to a more thorough analysis of the elements of a multimedia piece and the interrelationships among them.
} 
"The process is" as a sound object in-and-of-itself presents the feeling of leading forward to another sound object, hence its label "Propulsion: sound that pushes or pulls forward." The remaining cadence of the statement sounds like a completely predictable, natural end to the momentum created by the first part of the statement, thus the "Conclusive: predictable end to the energy of sound" label. ${ }^{13}$ Because this work is both aural and visual, there are visible clues that lead to a similar analysis. Figures 2 and 3 are screenshots of this phrase as it is spoken.

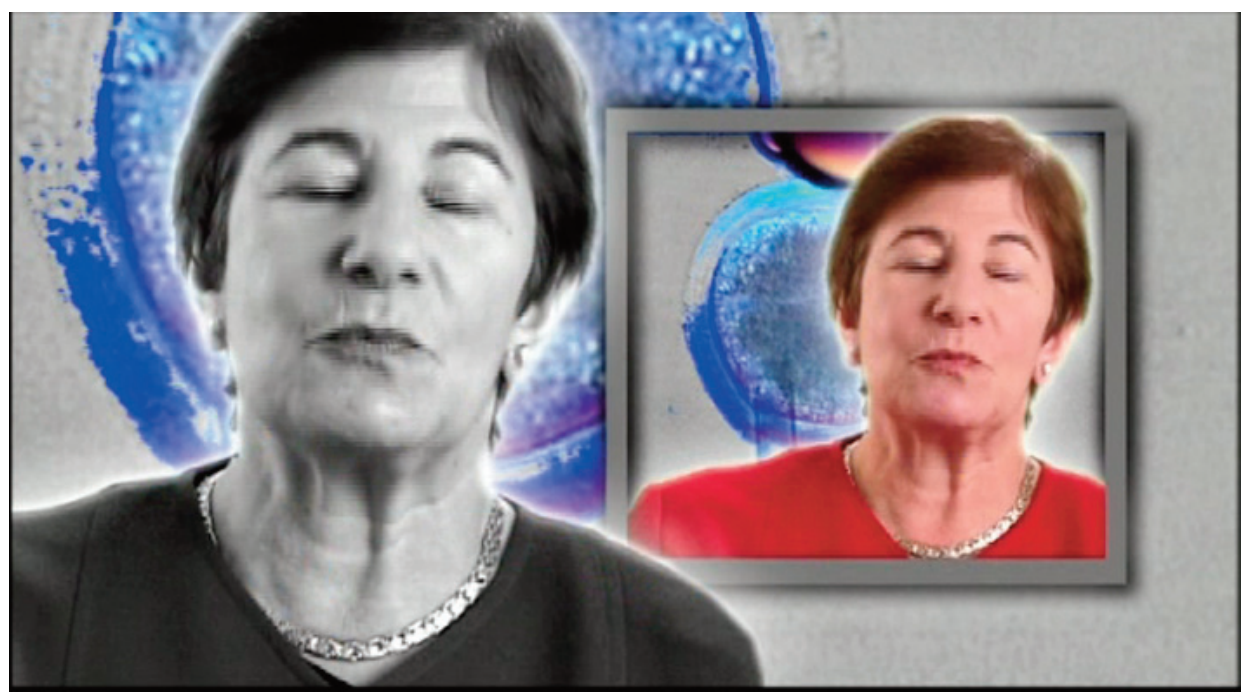

Figure 2. Screenshot at 38:51, Three Tales (“The process is...”)

When watching these images in motion, one can see the speakers head raise (see Figure 2) as if to pull the words she is about to speak into existence; she then lowers her head (as in Figure 3) to signal the conclusion of the statement. At 38:58, the speaker again says, "The process is", which again is labeled with the "Propulsion" UST; however, this time, there is no matching conclusion. These observations are then laid out in a descriptive map, ${ }^{14}$ allowing for a clearer comparison of of sonic material (see Figure 4). This descriptive map fills a ubiquitous void often

${ }^{13}$ While the actual words are not predictable, as with most declarative statements spoken in English, one can assume there will be a general vocal cadence leading to the end of a statement. It is also important to note that in the phenomenological epoché, there is a distinction made between the semantic meaning of the sound and the essential, morphological qualia of the sound; therefore, one would ignore the implied meaning of the statement "The process is as follows:" (expecting something to follow) and simply examine the qualities of the sound itself. ${ }^{14}$ Cf. Lochhead, Judith. "'How Does It Work?' Challenges to Analytic Explanation." Music Theory Spectrum, 28/2 (Fall 2006), 233-254. 


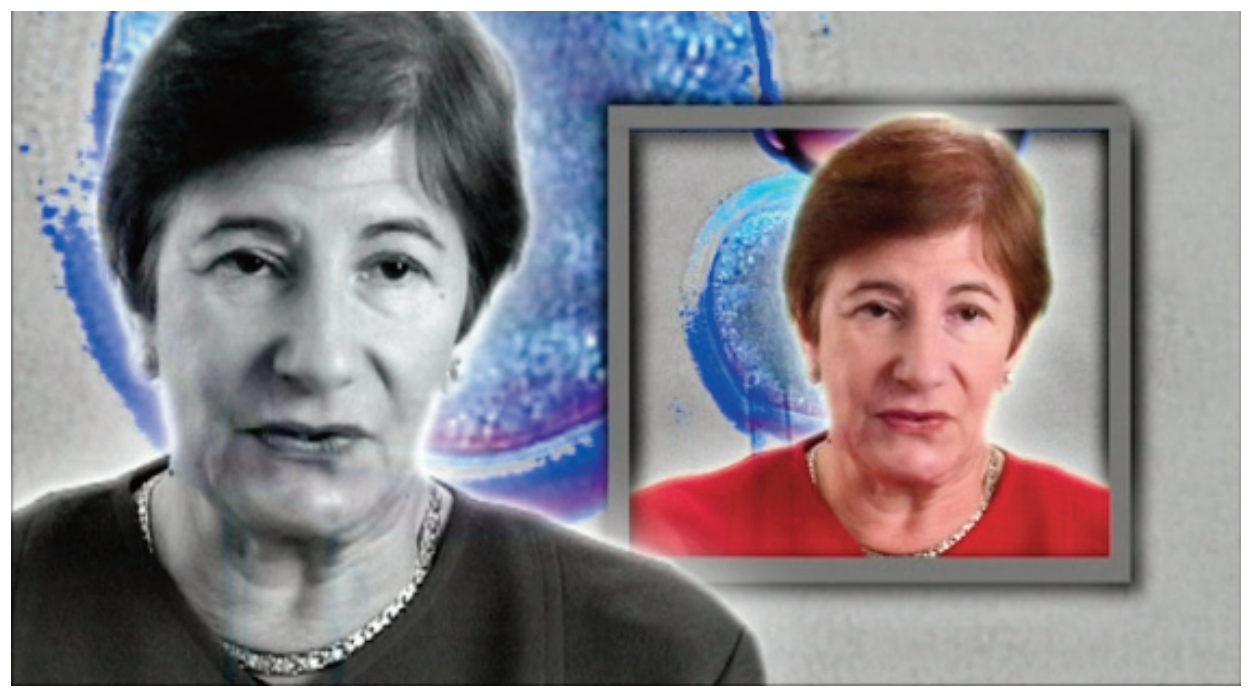

Figure 3. Screenshot at 38:53, Three Tales (“... as follows”)

associated with electronic multimedia - the lack of a score; at a primary level, the descriptive map provides a foundation upon which analyses can be built (ex. an examination of nested phenomenological structures, a survey of the use of certain USTs in a particular genre or style, an evaluation of the rationale behind choosing to describe a sound object with one UST rather than another, etc.).

Perhaps the most interesting elements of this piece do not lie in the sound objects or music alone, but rather in the extra-musical, cultural implications of the piece. In the "acousmatic", "epoche" listening of the piece, one would notice that there are different characters (including a robot) speaking through the scene. It is important to note that these characters are not actors hired to recite this text, but rather, they are world-renowned scientist, philosophers, and writers connected to the development of genetic engineering and the cloning of Dolly the Sheep. The robot singing at the beginning of this scene is Kismet, created at MIT and designed specifically to interact socially with humans. The first woman to appear on the screen, describing the cloning process is Ruth Deech, the chair of the U.K. Human Fertilization and Embryology Authority, Pro-Vice-Chancellor of Oxford University, and a Fellow of the Royal Society of Medicine; the other woman to appear in this scene is Gina Kolata, a science writer for the New York Times who first broke the story of Dolly in America. The first man to appear in the video, and who repeats "...are machines..., " is ethologist and evolutionary biologist Richard Dawkins, the first Charles Simonyi Professor of Public Understanding of Science at Oxford University; the other man to appear in this scene is James D. Watson, who with Francis Crick and Maurice Wilkins, won the Nobel Prize for their work 

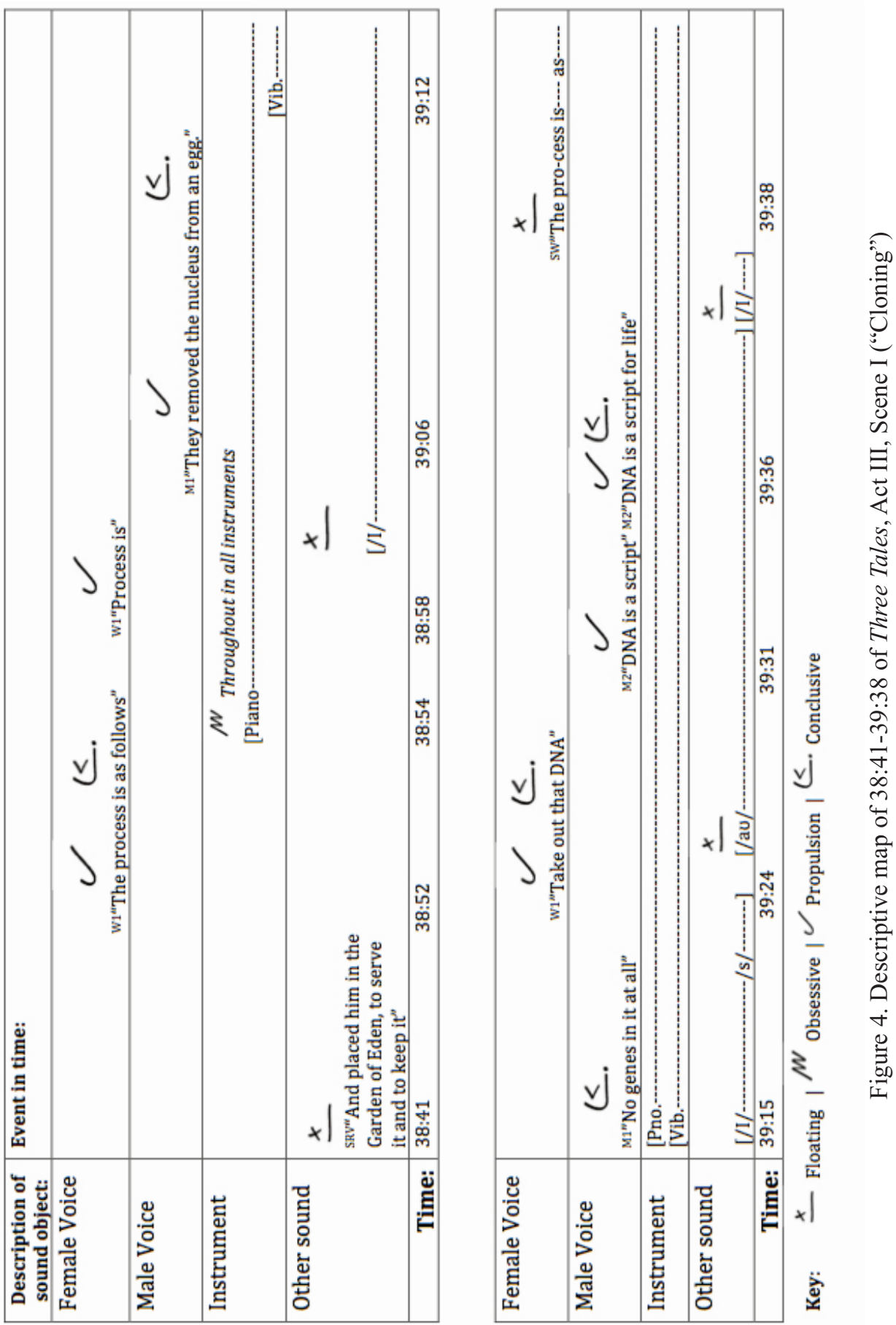
in discovering the structure of DNA. Knowing who is speaking this text lends a sort of gravitas and credibility to the interviews, effecting the perception (and by extension the experience) of the work.

Watching the visual elements of this work on DVD also provides some extramusical information that affects the experience of the scene. The scene on the DVD begins with Kismet singing; upon examination of the score, this entire act actually begins a moment after Kismet's solo, when Ruth Deech says "Process is as follows."

In watching the video, one notices the movement of the robot does not seem realistic, suggesting that the image is computer generated-as is the voice-and the affected, computerized singing contributes to this scientific, sterile aesthetic. Behind each of the interviewees are action scenes depicting the process of genetic engineering or cloning. While there are times in which the background video matches the steps in the process being described by the interviewees, there are also clips that are repeated, mimicking the music or repeated text. There are also times wherein there the screen is black with white writing; this stripping of other visual elements and replacing them with text alone occurs at other points within the entire video opera, symbolizing the divine, scripture, or other religious subtexts within the work. In this scene, Korot visually interjects the work "created" several times Richard Dawkins says the word "created", further accentuating references to the Garden of Eden.

While this is by no means an exhaustive analysis of this work, it does present a framework within which the phenomenological experience of this piece elucidates some particularly interesting aspects of this scene that would not be analyzable by means of other, traditional analytical techniques. In performing an initial bracketing of the sound objects and observing them as essential objects, a nuanced interpretation of the spatiotemporal and energetic experience of the text, constituent sound objects, and some of the visual elements of the piece was possible; further, adding some of the extra-musical elements associated to these sound and visual objects provided an additional level of interpretation. It is my hope that my expansion of the use of USTS as an analytical technique contributes to their acceptance as a viable tool in analyzing music, sonic art, and other works in other media, and leads to a deeper understanding of the phenomenological structure of time and movement in these works. 


\section{REFERENCES}

Austin, Michael, The Phenomenological Impact of Interface on the Analysis of Digital Music and Sonic Art, Ph.D. Dissertation, University of Texas at Dallas, 2011

Chion, Michel. Guide des objets sonores: Pierre Schaeffer et la recherche musicale, trans. John Dack and Christen North. 2009, Paris: INA-GRM, 1983, 30-31

Delalande, François, “Les Unités Sémiotiques Temporelles: Problématique et essai de definition”, Les Unités Sémiotiques Temporelles: Éléments nouveaux d'analyse musicale, Laboratoire Musique et Informatique de Marseille, 1996, 19.

Husserl, Edmund, Ideen zu einer reinen Phänomenologie und phänomenologishen Philosophie, Erstes Buch: Allgemeine Einfürung in die reine Phänomenologie (1913), Husserlania III, ed. K. Schuhmann (The Hague: Martinus Nijhoff, 1976); Ideas Pertaining to A Pure Phenomenology and to a Phenomenological Philosophy, First Book: General Introduction to a Pure Phenomenology, trans. F. Kersten, The Hague: Martinus Nijhoff, 1982, 32

Leigh Landy, Understanding the Art of Sound Organization, Cambridge, MA: The MIT Press, 2007, 190

Lochhead, Judith, “'How Does It Work?' Challenges to Analytic Explanation”, Music Theory Spectrum, 28/2, Fall 2006, 233-254

Reich, Steve, Three Tales, New York: Hendon Music, 2002 